\title{
Causes of maternal deaths at Tezpur medical college $\&$ hospital, Tezpur, Assam, India: a retrospective study
}

\author{
Rumen Chandra Boro ${ }^{1 *}$, Purashree Sarma ${ }^{1}$, Partha Sarathi Acharjee ${ }^{2}$
}

Assistant Professor ${ }^{1,2}$, PGT $^{2}$, Department of Obstetrics and Gynecology, Tezpur Medical College \& Hospital, Tezpur, Sonitpur, Assam 784010, India

Received: 15 March 2016

Revised: 20 March 2016

Accepted: 30 March 2016

*Correspondence:

Dr. Rumen Chandra Boro,

E-mail: drcboro@gmail.com

Copyright: (c) the author(s), publisher and licensee Medip Academy. This is an open-access article distributed under the terms of the Creative Commons Attribution Non-Commercial License, which permits unrestricted non-commercial use, distribution, and reproduction in any medium, provided the original work is properly cited.

\section{ABSTRACT}

Background: The present study was undertaken to find out the causes of maternal deaths in O\&G Department, TMCH, Tezpur, Assam.

Methods: Data for the study was collected from all maternal deaths, in patients attending both OPD as well as Emergency, occurred from March '2014 to February '2016 at TMCH, Tezpur.

Results: Out of total 52 maternal deaths; $28.85 \%$ are due to anaemia, $25 \%$ are due to Haemorrhage, $19.23 \%$ are due to Toxaemia. Obstructed labor and sepsis accounts for $9.61 \%$ of maternal deaths, each; unsafe abortion and other categories accounts for $3.84 \%$ of maternal deaths, each. Out of total maternal deaths, $86.5 \%$ belonged to rural areas, $21.2 \%$ are unbooked cases, $73.1 \%$ are poor literates and $67.3 \%$ are from poor socioeconomic groups. Out of 52 deaths, 50 cases died within $24 \mathrm{hrs}$.

Conclusions: In our study it is observed that anaemia, haemorrhage and toxaemia are the three major causes of maternal deaths in TMCH, Tezpur. Obstructed labour, sepsis, unsafe abortions, etc. are the causes of the rest of the maternal deaths. It is seen from the study that illiteracy, ignorance, unawareness, poor socioeconomic conditions, lack of antenatal checkups, non-availability of quality care set ups, and drawbacks in referral systems were the major causative factors.

Keywords: Maternal deaths, Haemorrhage, Tertiary care

\section{INTRODUCTION}

Maternal mortality is an important health indicator for any country. In India maternal mortality is still having a very high rate, i.e., 167 per Lakh live births (SRS 20112013), in comparison to 9 per Lakh in developed countries. ${ }^{1}$

Causes of maternal deaths are found to be different among countries. In developed countries major causes of maternal deaths are hypertensive disorders, haemorrhage and embolism. On the other hand, in developing countries major causes of maternal deaths are anaemia, haemorrhage, hypertensive disorders and sepsis. ${ }^{2}$
In India itself, different causes of maternal deaths are found in different regions. In northern India sepsis is the leading cause followed by haemorrhage, hypertensive disorders and anaemia. In southern India, haemorrhage is the leading cause followed by hypertensive disorders, sepsis and anaemia. In north-east India hypertensive disorders are the leading cause followed by haemorrhage, sepsis and anaemia. ${ }^{1}$ In Assam, the MMR is higher than the national rate, i.e. 300/Lakh live births. ${ }^{1}$ The MMR of Assam is highest among all the states. The aim of the study is to find out the causes of maternal deaths occurring in TMCH; Tezpur, from different communities, religions and socioeconomic conditions. 


\section{METHODS}

Data was collected for this retrospective study from all the maternal deaths that occurred from March '2014 to Feb. '2016 at TMCH, Tezpur, in patients attending both OPD as well as Emergency.

\section{Inclusion criteria}

1. Deaths resulting from complication of pregnancy itself, labour, during puerperium or within 42 days of termination of pregnancy, irrespective of site and duration of pregnancy. 2. Deaths resulting from disease present before or developed during pregnancy that was obviously aggravated by the pregnancy itself.

\section{Exclusion criteria}

1. Deaths from Accidents, Poisoning, Physical assault.

Method of collection of data was: 1 . Information obtained from the Patient's bed head tickets. 2. Information obtained from the patient's relative and from the ASHA concerned. Data were thus collected and analysed.

\section{RESULTS}

In our study, the total live births were 11,210 in the given period out of which total maternal deaths were 52 . Out of total 52 maternal deaths; $28.85 \%$ are due to anaemia, $25 \%$ are due to Haemorrhage, $19.23 \%$ are due to Toxaemia. Obstructed labour and sepsis accounts for $9.61 \%$ of maternal deaths, each; unsafe abortion and other categories accounts for $3.84 \%$ of maternal deaths, each. Out of 52 maternal deaths, 48 cases are from rural areas $(92.31 \%)$ and 4 cases from the urban areas $(7.69 \%)$.

In our study, most of the maternal deaths are from the age group of more than 20 years $(69.2 \%)$. More maternal deaths were found from the groups attended primary school or below $(73.1 \%)$.

Study groups having a family income of $<15,000 /$ month were found to have more maternal deaths (Table 1). In the study more maternal deaths are encountered in the groups having no or irregular antenatal check-ups $(21.2 \%)$.

The quality of the referral system of the complicated pregnancy cases to $\mathrm{TMCH}$ from the periphery areas also affected to a great extent in the causation of the maternal deaths. Out of 52 cases, 22 cases were referred to TMCH with strong maternal complications $(42.3 \%)$ at admission.

In the study, out of 52 deaths 17 maternal deaths occurred within a time period of $<4 \mathrm{hrs}$. $(32.6 \%)$ and 33 maternal deaths were found in between 4-24 hrs (63.5\%).
Table 1: Different features of study group.

\begin{tabular}{|c|c|c|c|}
\hline \multicolumn{2}{|c|}{ Categories } & Number & $\%$ \\
\hline \multicolumn{2}{|c|}{ Total no. of maternal deaths } & 52 & \\
\hline \multicolumn{2}{|c|}{ Total no. of live births } & 11,210 & \\
\hline \multirow{2}{*}{ Residence } & Rural & 45 & 86.5 \\
\hline & Urban & 7 & 13.5 \\
\hline \multirow{2}{*}{ Age } & 20 yrs or below & 16 & 30.8 \\
\hline & $>20 \mathrm{yrs}$ & 36 & 69.2 \\
\hline \multirow{2}{*}{$\begin{array}{l}\text { Educational } \\
\text { Status }\end{array}$} & $\begin{array}{l}\text { Primary school } \\
\text { or below }\end{array}$ & 38 & 73.1 \\
\hline & $\begin{array}{l}\text { High School or } \\
\text { above }\end{array}$ & 14 & 26.9 \\
\hline \multirow{2}{*}{$\begin{array}{l}\text { Family } \\
\text { Income }\end{array}$} & $<15,000 /$ month & 35 & 67.3 \\
\hline & $\begin{array}{l}>/=15 \\
000 / \text { month }\end{array}$ & 17 & 32.6 \\
\hline \multirow{3}{*}{$\begin{array}{l}\text { ANC } \\
\text { received }\end{array}$} & No ANC & 11 & 21.2 \\
\hline & $<3 \mathrm{ANC}$ & 28 & 53.8 \\
\hline & 3 or more $\mathrm{ANC}$ & 13 & 25 \\
\hline \multirow{2}{*}{ Referral } & Referred & 22 & 42.3 \\
\hline & Direct admission & 30 & 57.7 \\
\hline \multirow{2}{*}{ Parity } & Primi & 34 & 65.4 \\
\hline & Multi & 28 & 53.8 \\
\hline \multirow{3}{*}{$\begin{array}{l}\text { Admission to } \\
\text { death } \\
\text { interval }\end{array}$} & $<4 \mathrm{hrs}$ & 17 & 32.6 \\
\hline & $4-24 \mathrm{hrs}$ & 33 & 63.5 \\
\hline & 1-7 days & 2 & 3.8 \\
\hline
\end{tabular}

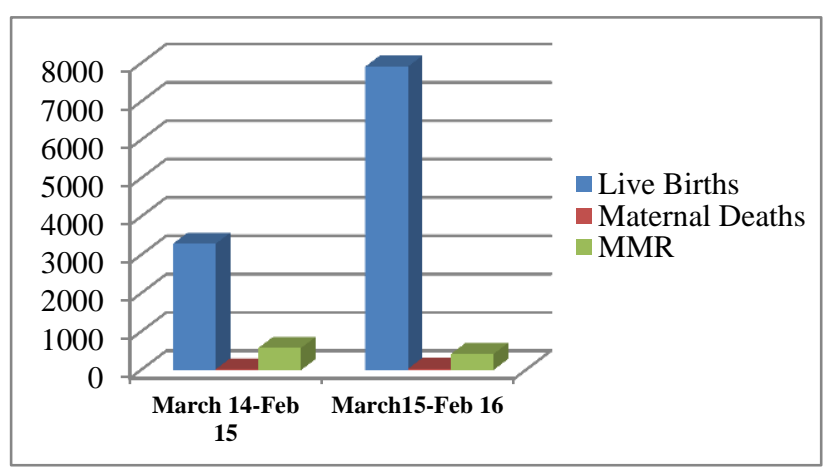

Figure 1: Histogram showing yearly distribution of maternal deaths in TMCH, Tezpur (from March 2014 to Feb 2015 \& March 2015 to Feb 2016).

Table 2: Disease-wise distribution of maternal deaths in TMCH.

\begin{tabular}{|lll|}
\hline Causes of maternal deaths & No. of deaths & $\%$ \\
\hline Anaemia & 15 & 28.85 \\
\hline Haemorrhage & 13 & 25 \\
\hline Toxaemia & 10 & 19.23 \\
\hline Obstructed labour & 5 & 9.61 \\
\hline Sepsis & 5 & 9.61 \\
\hline Unsafe abortion & 2 & 3.84 \\
\hline Others & 2 & 3.84 \\
\hline Total & 52 & \\
\hline
\end{tabular}




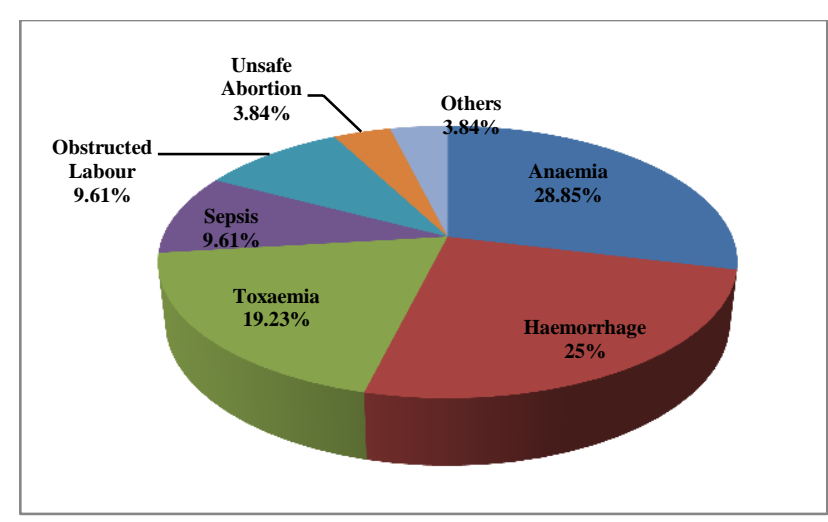

Figure 2: Pie diagram showing causes of maternal mortality in TMCH.

\section{DISCUSSION}

In the present study we found that the maternal mortalities in TMCH are mainly due to anaemia, haemorrhage, toxaemia, obstructed labour and sepsis. We found total maternal death in the said period is 52 in a total live birth of 11,210 . Thus the MMR is 464 . The MMR in Assam is 300 [SRS 2011-2013] and MMR in India is 167 [SRS 2011-2013].

TMCH being a rural tertiary referral centre is thus having a high MMR. More higher MMRs were found by Goswami et al from Guwahati Medical College \& Hospital in 1994, S. K. Bera, et al from Kolkata in 1990, Sharmishta et al from Silchar in 1995 and Shanti Roy, et al from Patna in 1998, showing MMRs of 1234/Lakh live births, 1023/Lakh live births, 2089/Lakh live births and 2667/Lakh live births, respectively. ${ }^{3-6}$ However, K. Pratima, et al from Manipur in 2012 found an MMR of 90.45/Lakh live births; which is much lower than our study. ${ }^{7}$

In the study, we found most common cause of maternal deaths in TMCH is due to Anaemia $(28.85 \%)$ which is multifactorial in origin. Mukherjee et al in 1996-2006 and Verma Ashok, et al in 1995-2005 found a similar result of $25.40 \%$ and $15.40 \%$, respectively. ${ }^{8,9}$ Anaemia is the leading cause of maternal deaths occurring in $\mathrm{TMCH}$ because of multiple factors which includes poor socioeconomic conditions, malnutrition, irregular ANCs, repeated child births with inadequate spacing and poor literacy rates.

Next to it, Haemorrhage is the major cause $(25 \%)$ of maternal deaths. Arpita $\mathrm{N}$ et al in 2006-2010 and Vidhydhar et al in 2006-2010 found $31.9 \%$ and $21.05 \%$, respectively. ${ }^{10,11}$ In $\mathrm{TMCH}$ the high rates of Haemorrhage related maternal deaths are due to late detection and inability to reach $\mathrm{TMCH}$ at proper time from the referring centre for proper intervention. Patients with pre-existing anaemia along with haemorrhage leads to more maternal deaths. Haemorrhagic causes of maternal deaths include deaths resulting from APH, PPH, Ectopic pregnancy, Incomplete Abortions and Ruptured Uterus.

Toxaemia is the third common cause of maternal deaths (19.23\%). Verma Ashok, et al in 1995-2005 and Puri, et al in 2003-2006 found a similar result of $20 \%$ and $18 \%$ of maternal deaths due to toxaemia, respectively. ${ }^{9,12}$ This is mainly due to irregular ANCs and lack of compliance to treatment in the patient's study group. Obstructed labour (9.61\%), Sepsis (9.61\%), Unsafe Abortion (3.84\%) and others $(3.84 \%)$ comes in magnitude as causes leading to maternal deaths in TMCH, Tezpur. Maternal deaths due to obstructed labour in our study are mainly due to late referral of patients from periphery to $\mathrm{TMCH}$.

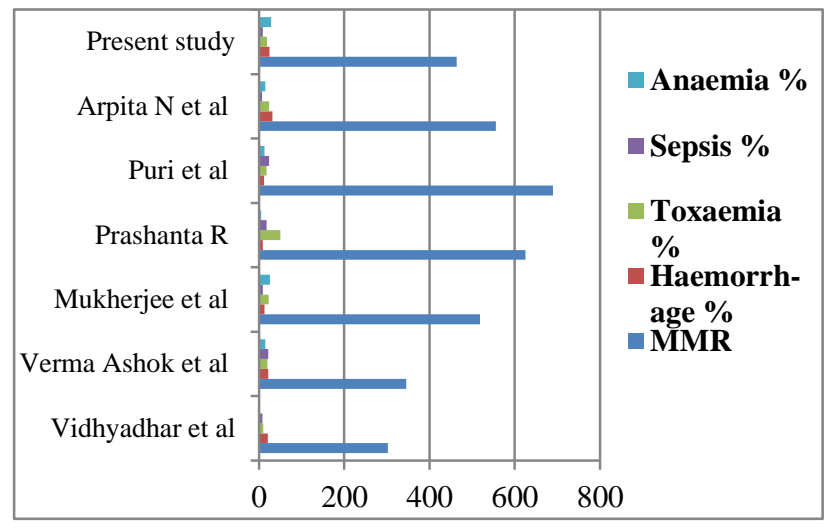

Figure 3: Bar Diagram showing comparative analysis of maternal death causes.

Table 3: Comparative analysis.

\begin{tabular}{|c|c|c|c|c|c|}
\hline Authors & MMR & Haemorrhage \% & Toxaemia \% & Sepsis \% & Anaemia \% \\
\hline Mukherjee et al 1996-2006, ${ }^{8}$ & 518.7 & 12.7 & 22.97 & 9.45 & 25.40 \\
\hline Verma Ashok et al 1995-2005, ${ }^{9}$ & 345.9 & 21.8 & 20 & 21.6 & 15.4 \\
\hline Arpita $\mathrm{N}$ et al $2006-2010,^{10}$ & 555.5 & 31.9 & 24.2 & 7.24 & 14.95 \\
\hline Vidhyadhar et al 2006-2010, & 302.6 & 21.05 & 10.25 & 7.89 & 2.63 \\
\hline Puri et al 2003-2006, ${ }^{12}$ & 690 & 12 & 18 & 24 & 13 \\
\hline Prashanta R 2005, ${ }^{13}$ & 625 & 9.22 & 50.56 & 18.17 & 4.8 \\
\hline Present study & 463.9 & 25 & 19.23 & 9.61 & 28.85 \\
\hline
\end{tabular}




\section{CONCLUSIONS}

From our study, it is found that anaemia is the major cause of maternal deaths. This is accounted to the fact that TMCH, Tezpur is a rural tertiary referral centre, where most of the patients are coming from the rural areas with poor nutrition, lack of awareness, poor education, inadequate birth spacing and irregular ANCs. Most importantly, well equipped referring and transporting systems are lagging behind. Early detection of PIH and its proper management can reduce maternal deaths due to toxaemia. Haemorrhage especially during post-partum period is sudden and unpredictable and is more dangerous when women are having pre-existing anaemia. Higher prevalence of anaemia and nonavailability of blood in blood bank were the important factors in deaths from haemorrhage. Active management of third stage of labour can prevent many of these deaths. Sepsis is probably the most easily preventable cause of maternal deaths. Practice of proper asepsis and antiseptic care during delivery with reasonable use of antibiotics can prevent maternal deaths from sepsis. Regular ANCs and active participation of ASHAs and other health/social workers can reduce the burden of maternal deaths to a great extent.

Funding: No funding sources Conflict of interest: None declared

Ethical approval: The study was approved by the Institutional Ethics Committee

\section{REFERENCES}

1. Govt. Of India (Sample Registration System). Maternal Mortality in India 2011-2013. New Delhi: Registrar General, India. 2013.

2. Bhuyan R, Deka G, Das GC, Baruah RR, Majumdar M. The impact of health care system on maternal mortality- a tertiary hospital based study. The New Indian Journal of OBGYN. 2016;2(2):110-4.
3. Goswami A, Kalita H: Maternal Mortality at Guwahati Medical College \& Hospital. J Obs Gyn India. 1996;46(6):785-90.

4. Bera SK, Sengupta A. Evaluation of etiological factors of Maternal Mortality. J of Obs Gyn India. 1991:182-88

5. Bhattacharjee S. Maternal Mortality, 10 year review, a decade of safe motherhood. $\mathbf{J}$ of Obs Gyn India. 2001;51(3):108-10.

6. Roy S, Singh A, Pandey A, Roy H, Roy S, Roy S. Maternal Mortality in Apex Hospital, Bihar. J Obs Gyn India. 2002;52(1):100-4.

7. Devi KP, Singh CM, Devi SR. Maternal Mortality and its causes in tertiary centre. J Obs Gyn India. 2012;62(2):168-71.

8. Mukherjee S, Theengh C, Bhattacharya S, Maru L. Maternal mortality at a tertiary care institute of central India. Asian Journal of Obst \& Gynae practice. 2010;4:23-7.

9. Verma A, Minhas S, Sood A. A study on maternal mortality in Dr. Rajendra Prasad Govt. M.C. Tanda Dist. Kangra, H.P. Indian J Obst Gynecol. 2008;58(3):226-9.

10. Arpita N. A retrospective and prospective study of maternal mortality in a rural tertiary care hospital of Central India. Indian Journal of community Health. 2013;25,1.

11. Vidhyadhar B, Purushottam A, Giri B, Garg RC. Maternal Mortality at a tertiary care teaching hospital of rural India, a retrospective study. Int J Biol Med Res. 2011;2(4):1043-6.

12. Puri A, Yadav I, Jain N. Maternal mortality in an urban tertiary care hospital of North India. Indian Journal of Obst Gynnecol. 2011;61(3):280-5.

13. Pal A, Prasantha R, Samir H, Mondal TK. Review of changing trends in maternal mortality in a rural medical college of West Bengal. J Obst Gynecol Ind. 2005;55(6):521-4.

Cite this article as: Boro RC, Sarma P, Acharjee PS. Causes of maternal deaths at Tezpur medical college \& hospital (TMCH), Tezpur, Assam, India: a retrospective study. Int J Reprod Contracept Obstet Gynecol 2016;5:1006-9. 